\title{
Extensive Darier Disease Successfully Treated with Doxycycline Monotherapy
}

\author{
Alicia Sfecci ${ }^{a} \quad$ Camille Orion $^{a} \quad$ Laure Darrieux $^{a} \quad$ Laurent Tisseau $^{b}$ \\ Gilles Safa ${ }^{a}$ \\ ${ }^{a}$ Department of Dermatology, Centre Hospitalier de Saint-Brieuc, Saint-Brieuc, and \\ ${ }^{\mathrm{b}}$ Armor Pathology Laboratory, Plérin, France
}

\section{Key Words}

Darier disease $\cdot$ Doxycycline $\cdot$ Treatment

\begin{abstract}
Darier disease (DD) is a rare dominantly inherited genodermatosis characterized by loss of intercellular adhesion (acantholysis) and abnormal keratinization. DD is often difficult to manage. Numerous treatments have reportedly been used for the treatment of DD, with limited success. Systemic retinoids are considered the drug of choice for treating DD. However, their use is limited by potential deleterious side effects. Considering the recently reported efficacy of doxycycline for Hailey-Hailey disease, an inherited acantholytic skin disorder pathogenetically similar to $\mathrm{DD}$, we report the case of a patient with extensive DD who showed a dramatic response to oral doxycycline monotherapy.

(C) 2015 The Author(s)

Published by S. Karger AG, Basel
\end{abstract}

\section{Introduction}

Darier disease (DD) is a rare, autosomal dominant, inherited acantholytic dermatosis caused by a mutation in the ATP2A2 gene on chromosome 12 [1]. DD usually exhibits a chronic course with exacerbations and remissions. The diagnosis of DD is suggested by the clinical findings of a persistent eruption of greasy hyperkeratotic papules and plaques usually occurring over seborrheic areas as well as distinctive nail abnormalities. Mucous membranes can also be affected. The treatment of DD can be challenging and is often difficult and unsatisfactory [2]. Numerous treatments such as topical corticosteroids, topical retinoids, topical 5-fluorouracil, diclofenac sodium 3\% gel, dermabrasion and laser therapy have re- 
Sfecci et al.: Extensive Darier Disease Successfully Treated with Doxycycline Monotherapy

portedly been used for the treatment of DD, with limited success. Systemic retinoids, including acitretin, isotretinoin and alitretinoin, are the most effective treatment for DD. However, their use is limited by potential deleterious side effects. Considering the recently reported efficacy of doxycycline for Hailey-Hailey disease [3], an inherited acantholytic skin disorder pathogenetically similar to DD, we report the case of a patient with extensive DD who showed a dramatic response to oral doxycycline monotherapy.

\section{Case Report}

A 77-year-old patient with a 57-year history of DD was referred to our department for a severe exacerbation of DD that was recalcitrant to conventional topical treatments, including emollients, topical corticosteroids and topical mupirocin ointment. The patient's father and son were also affected by DD. Physical examination revealed malodorous eroded hyperkeratotic papules and plaques on the axillae, groin, perineum and lower back (fig. 1). Classical nail changes, which included white and red longitudinal bands, were present. The mucosa was not affected. A skin biopsy specimen from a lower back lesion showed characteristic histopathological findings consistent with a diagnosis of DD (fig. 2). A therapeutic regimen of oral doxycycline $(100 \mathrm{mg} /$ day $)$ was started. The patient was instructed to use only bland emollients as concomitant topical therapy. The treatment was well tolerated and produced no side effects. Within 2 weeks the skin lesions showed marked improvement and were in complete remission after 1 month (fig. 3). The patient was maintained on a half-dose therapy (50 mg/day) and did not experience any relapse within 3 months of follow-up.

\section{Discussion}

DD is caused by mutations in the ATP2A2 gene that encodes the sarcoplasmic/endoplasmic reticulum calcium ATPase 2 (SERCA2), which is a calcium pump. SERCA2 plays a central role in cellular calcium homeostasis and actively transports calcium ions from the cytosol into the lumen of the endoplasmic reticulum in order to maintain a low cytoplasmic calcium level [4]. The molecular mechanisms by which specific ATP2A2 mutations alter the function of the SERCA2 protein and cause acantholysis (loss of cell-to-cell adhesion) and dyskeratosis (premature and abnormal keratinization), the histological hallmarks of DD, remain unclear. As a consequence of the loss of SERCA2 calcium transport, Darier keratinocytes display depleted endoplasmic reticulum calcium stores [5]. In addition, extracellular calcium is important for epidermal differentiation and intraepidermal cohesion [6].

Doxycycline belongs to the tetracycline family. In addition to their antibiotic potential, tetracyclines and their analogues exhibit anti-inflammatory properties by inhibiting granulocyte chemotaxis and secretion. They also display anti-collagenase activity by inhibiting matrix metalloproteinases [7]. Interestingly, matrix metalloproteinase 9 and its inhibitor, tissue inhibitor of metalloproteinase 1, have been shown to be involved in DD and HaileyHailey disease [8]. Moreover, tetracyclines possess powerful metal chelation properties. Tetracyclines bind divalent metal cations and circulate in blood plasma primarily as calcium and magnesium chelators. Furthermore, once chelated, tetracyclines can act as ionophores that are capable of transporting bound calcium and magnesium through lipophilic phases, such as cellular membranes, and delivering ions into intracellular compartments. After intracellular incorporation, calcium can act as a secondary messenger and affect pathways, such as those involved in secretory processes, receptor activation or inhibition, cell division 
Sfecci et al.: Extensive Darier Disease Successfully Treated with Doxycycline Monotherapy

and metabolic reactions $[7,9]$. It can be hypothesized that these chelation properties can affect the release of calcium from storage organelles such as sarcoplasmic/endoplasmic reticulum and act on the molecular mechanisms involved in the disruption of calcium homeostasis in Darier keratinocytes, leading to the clinical symptoms of the disease.

Due to its non-antibiotic properties and favorable safety profile compared to oral retinoids, doxycycline may be an interesting treatment option for DD. Further studies are warranted to confirm these findings and to assess the efficacy of oral doxycycline in the treatment of DD.

\section{Statement of Ethics}

The authors have no ethical conflicts to disclose.

\section{Disclosure Statement}

The authors have no conflicts of interest to disclose. No financial support was obtained for this work.

\section{References}

1 Sakuntabhai A, Ruiz-Perez V, Carter S, Jacobsen N, Burge S, Monk S, Smith M, Munro CS, O'Donovan M, Craddock N, Kucherlapati R, Rees JL, Owen M, Lathrop GM, Monaco AP, Strachan T, Hovnanian A: Mutations in ATP2A2, encoding a Ca ${ }^{2+}$ pump, cause Darier disease. Nat Genet 1999;21:271-277.

-2 Sehgal VN, Srivastava G: Darier's (Darier-White) disease/keratosis follicularis. Int J Dermatol 2005;44: 184-192.

-3 Le Saché-de Peufeilhoux L, Raynaud E, Bouchardeau A, Fraitag S, Bodemer C: Familial benign chronic pemphigus and doxycycline: a review of 6 cases. J Eur Acad Dermatol Venereol 2014;28:370-373.

4 Hovnanian A: SERCA pumps and human diseases. Subcell Biochem 2007;45:337-363.

5 Foggia L, Aronchik I, Aberg K, Brown B, Hovnanian A, Mauro TM: Activity of hSPCA1 Golgi Ca ${ }^{2+}$ pump is essential for $\mathrm{Ca}^{2+-}$ mediated $\mathrm{Ca}^{2+}$ response and cell viability in Darier disease. J Cell Sci 2006;119:671-679.

-6 Savignac M, Edir A, Simon M, Hovnanian A: Darier disease: a disease model of impaired calcium homeostasis in the skin. Biochim Biophys Acta 2011;1813:1111-1117.

7 Sapadin AN, Fleischmajer R: Tetracyclines: nonantibiotic properties and their clinical implications. J Am Acad Dermatol 2006;54:258-265.

-8 Kobayashi T, Sakuraoka K, Hattori S, Hori H, Nagai Y, Tajima S, Nishikawa T: Immunolocalization of human gelatinase (type IV collagenase, MMP-9) and tissue inhibitor of metalloproteinase 1 in Hailey-Hailey and Darier's diseases. Dermatology 1996;193:110-114.

-9 Nelson ML: Chemical and biological dynamics of tetracyclines. Adv Dent Res 1998;12:5-11. 


\section{Case Reports in Dermatology}

Sfecci et al:: Extensive Darier Disease Successfully Treated with Doxycycline Monotherapy

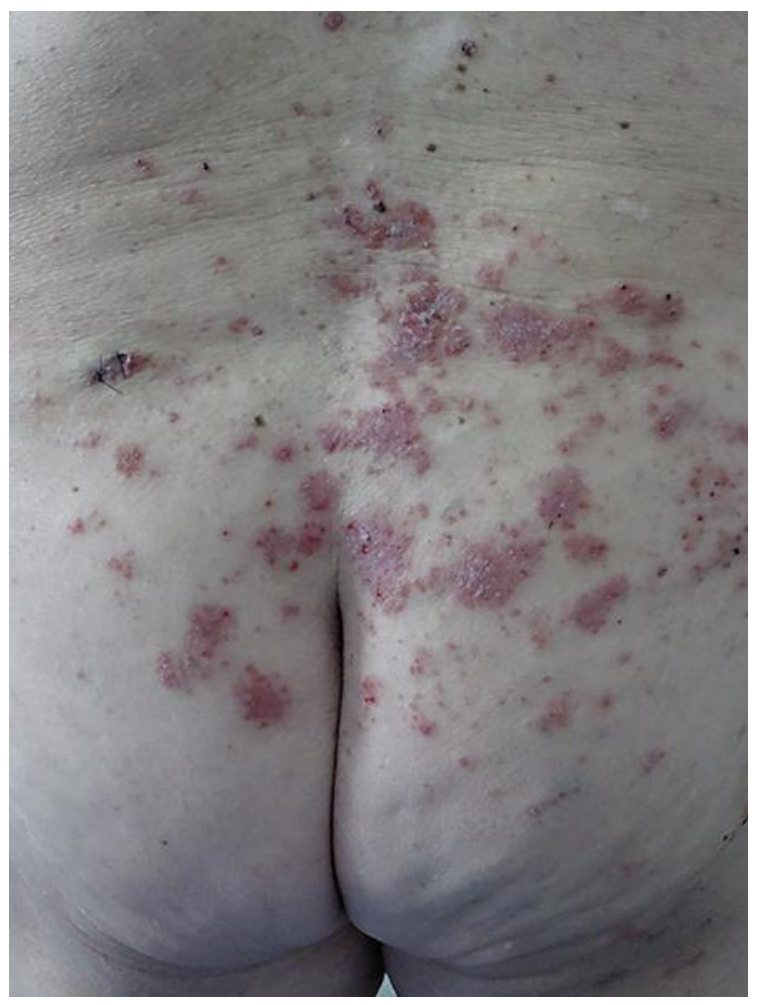

Fig. 1. Lower back before treatment with doxycycline.

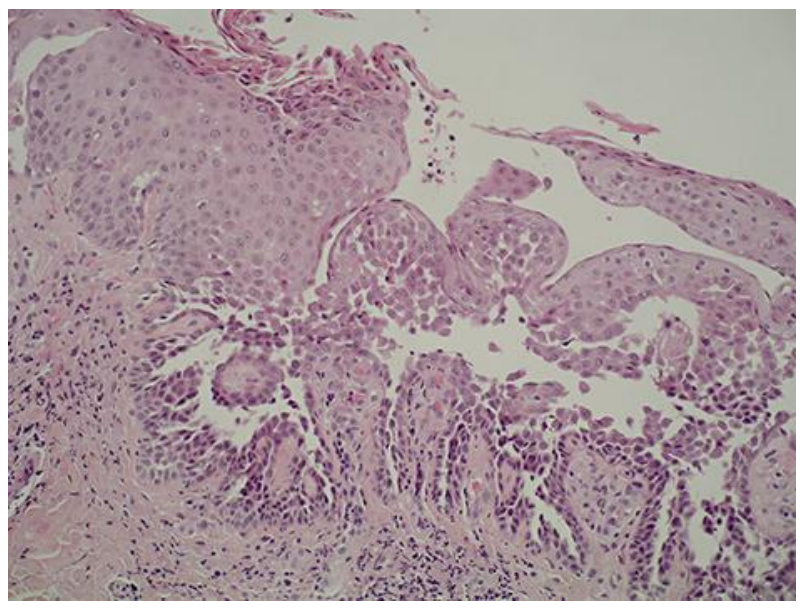

Fig. 2. Histopathology of a lesional skin biopsy from the lower back showing the presence of hyperkeratosis, papillomatosis, dyskeratosis with corps ronds and grains, and acantholysis with suprabasal cleft formation. HE. $\times 200$. 
Case Reports in
Dermatology

Case Rep Dermatol 2015;7:311-315

DOI: $10.1159 / 000441467$

(C) 2015 The Author(s). Published by S. Karger AG, Basel www.karger.com/cde

Sfecci et al.: Extensive Darier Disease Successfully Treated with Doxycycline Monotherapy

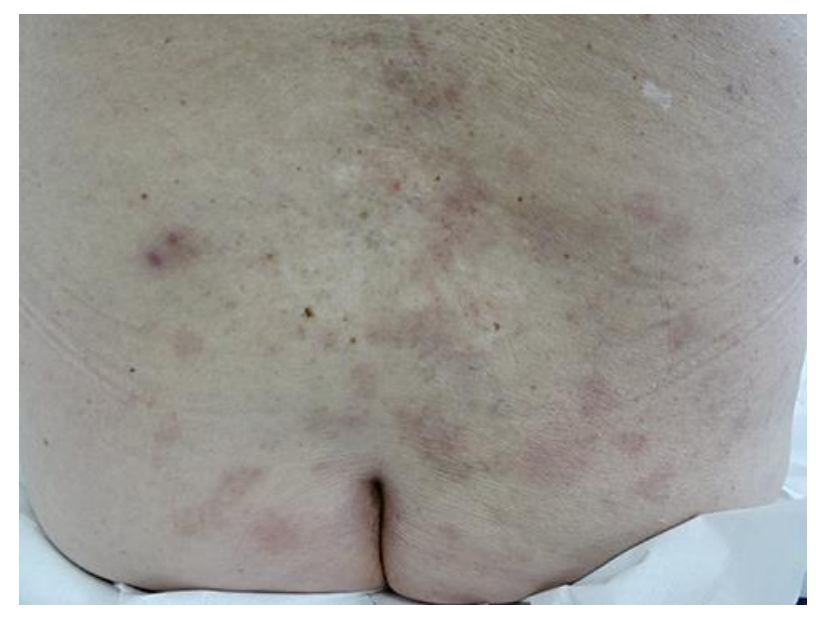

Fig. 3. Lower back after 1 month of oral doxycycline monotherapy. 